\title{
The National Survey of Trabeculectomy. II. Variations in operative technique and outcome
}

Abstract

Purpose There is a considerable body of literature relating to trabeculectomy; however, there are no data representative of the national experience of trabeculectomy in the United Kingdom (UK). The Department of Health funded a national survey of trabeculectomy to establish current practice patterns and the outcome of trabeculectomy in the National Health Service (NHS). In this paper we report variations in surgical technique and the national success rate of trabeculectomy. Methods A cross-sectional survey was carried out of consultant ophthalmologists performing trabeculectomy in the NHS. Participants recruited their four most recent consecutive first-time trabeculectomy cases according to study eligibility criteria and data were collected by self-administered questionnaire. Follow-up: 1 year posttrabeculectomy. Main outcome measure of success: final intraocular pressure (IOP) less than two-thirds the pre-operative IOP. Secondary outcome measures of success: final IOP less than $21 \mathrm{mmHg}$ and visual field stability. Success was further defined as unqualified (excluding patients on antiglaucoma medications at final follow-up) or qualified (including patients on anti-glaucoma medications at final follow-up). The relationship between variables characterising consultants' practice and main outcome measure was examined by chi-square test. Results Clinical outcome data were available for $1240(85.3 \%)$ cases. There were wide variations in operative technique. The mean post-operative IOP was $14.4 \mathrm{mmHg}(95 \%$ CI 14.2-14.7), which is a mean reduction of $11.8 \mathrm{mmHg}$ (95\% CI 11.4-12.2). An unqualified success, in terms of the main outcome measure, was achieved in $66.6 \%$ of patients and a qualified success in $71.0 \%$ of cases. An unqualified success, in terms of a final IOP less than $21 \mathrm{mmHg}$, was achieved in $84.0 \%$ of cases and a qualified success in $\mathbf{9 2 . 0} \%$. Visual fields were stable in $\mathbf{8 4 . 2} \%$. Outcome was not related to consultants' specialist interest, level of activity, type of hospital or region.

Conclusions The success rates reported in this paper represent the national experience of first-time trabeculectomy for open angle glaucoma in the UK. The national success rate at 1 year compares favourably with many studies in the literature. This survey provides valid and clinically relevant measures of success for the production of guidelines and standards for audit at regional, local and individual level and a baseline for the comparison of new therapies.

Key words Intraocular pressure, National survey, Outcomes, Trabeculectomy

The National Survey of Trabeculectomy is a large cross-sectional study of current practices of trabeculectomy in the United Kingdom (UK). Although there are many reports in the literature of the outcome of trabeculectomy, most are single-surgeon series and are restricted to specific clinic populations. This survey was designed to provide evidence of the practice of ophthalmologists performing trabeculectomy and the outcomes of first-time trabeculectomy relevant to a UK population of patients and practitioners. The first report from this survey described survey methods, the demography and the clinical characteristics of the sample. ${ }^{1}$ In this paper we describe variations in the operative technique and the outcome of trabeculectomy in terms of success.

The vast range of definitions of trabeculectomy success used in the literature is testimony to the difficulty of determining an appropriate outcome measure for this operation. Ultimately the aim of surgery must be to retard or halt glaucomatous visual field loss. However, the performance and interpretation of visual fields is highly problematic and detection of progression is difficult even in experienced hands. ${ }^{2}$ Intraocular pressure (IOP) is easier to measure than visual field progression and has been used as a surrogate measure of surgical success since the introduction of trabeculectomy. Historically, success is usually reported in terms of a postoperative IOP reduction below a level of around $21 \mathrm{mmHg}$ although increasingly tonometric outcome measures that use a proportionate criterion are being used. ${ }^{3-10}$
B. Edmunds Royal College of Ophthalmologists London, UK

\section{J.R. Thompson} Department of Ophthalmology Leicester University Leicester, UK

J.F. Salmon Oxford Eye Hospital Oxford, UK

\section{R. Wormald}

Department of Ophthalmic Epidemiology and International Eye Health Institute of Ophthalmology London, UK

Beth Edmunds Royal College of Ophthalmologists 17 Cornwall Terrace London NW1 4QW, UK Tel: $+44(0) 2079350702$ Fax: +44 (0)20 9359838 e-mail: beth@ukonline.co.uk

Funded by the Department of Health

Presented in part at the Royal College of Ophthalmologists Annual Congress, 1998

Received: 16 October 2000 Accepted in revised form: 6 March 2001 


\section{Methods}

All consultant ophthalmologists performing trabeculectomy in the UK were invited to select the four most recent consecutive trabeculectomies performed on patients under their care prior to 18 June 1996. Data were collected by self-administered questionnaires at baseline and 6 and 12 months post-operatively. A detailed description of the methods, including validation and non-response studies, is published elsewhere. ${ }^{1}$ The main outcome measure of trabeculectomy success was defined as an IOP at 1 year following trabeculectomy of less than two-thirds the pre-operative IOP (as measured when listing the patient for surgery). Secondary outcome measures of success were an IOP less than $21 \mathrm{mmHg}$ (to

Table 1. Variation in operative features

\begin{tabular}{|c|c|c|c|}
\hline Variable & Category & Number & $\%$ \\
\hline Eye & $\begin{array}{l}\text { Right } \\
\text { Left } \\
\text { Missing data }\end{array}$ & $\begin{array}{r}627 \\
613 \\
0\end{array}$ & $\begin{array}{l}50.6 \\
49.4\end{array}$ \\
\hline Anaesthetic & $\begin{array}{l}\text { General anaesthetic } \\
\text { Peribulbar } \\
\text { Retrobulbar } \\
\text { Subconjunctival } \\
\text { Sub-Tenon's } \\
\text { Topical } \\
\text { Missing data }\end{array}$ & $\begin{array}{r}424 \\
555 \\
105 \\
38 \\
59 \\
6 \\
53\end{array}$ & $\begin{array}{r}35.7 \\
46.8 \\
8.8 \\
3.2 \\
5.0 \\
0.5\end{array}$ \\
\hline Grade of surgeon & $\begin{array}{l}\text { Consultant } \\
\text { Senior registrar } \\
\text { Registrar } \\
\text { Senior house officer } \\
\text { Associate specialist } \\
\text { Other } \\
\text { Missing data }\end{array}$ & $\begin{array}{r}727 \\
99 \\
199 \\
115 \\
55 \\
45 \\
0\end{array}$ & $\begin{array}{r}58.6 \\
8.0 \\
16.0 \\
9.3 \\
4.4 \\
3.6\end{array}$ \\
\hline Site of trabeculectomy & $\begin{array}{l}\text { Superior } \\
\text { Supero-nasal } \\
\text { Supero-temporal } \\
\text { Missing data }\end{array}$ & $\begin{array}{r}946 \\
136 \\
109 \\
50\end{array}$ & $\begin{array}{r}79.5 \\
11.4 \\
9.2\end{array}$ \\
\hline Traction suture & $\begin{array}{l}\text { Yes } \\
\text { No } \\
\text { Missing data }\end{array}$ & $\begin{array}{r}1034 \\
109 \\
97\end{array}$ & $\begin{array}{r}90.5 \\
9.5\end{array}$ \\
\hline & $\begin{array}{l}\text { Cornea } \\
\text { Superior rectus } \\
\text { Missing data }\end{array}$ & $\begin{array}{r}103 \\
924 \\
7\end{array}$ & $\begin{array}{l}10.0 \\
90.0\end{array}$ \\
\hline Conjunctival flap base & $\begin{array}{l}\text { Fornix } \\
\text { Limbus } \\
\text { Missing data }\end{array}$ & $\begin{array}{r}874 \\
350 \\
16\end{array}$ & $\begin{array}{l}71.4 \\
28.6\end{array}$ \\
\hline Paracentesis & $\begin{array}{l}\text { Yes } \\
\text { No } \\
\text { Missing data }\end{array}$ & $\begin{array}{r}411 \\
752 \\
77\end{array}$ & $\begin{array}{l}35.3 \\
64.7\end{array}$ \\
\hline Shape of scleral flap & $\begin{array}{l}\text { Rectangular } \\
\text { Triangular } \\
\text { Other } \\
\text { Missing data }\end{array}$ & $\begin{array}{r}943 \\
201 \\
53 \\
43\end{array}$ & $\begin{array}{r}78.8 \\
16.8 \\
4.4\end{array}$ \\
\hline Punch & $\begin{array}{l}\text { Yes } \\
\text { No } \\
\text { Missing data }\end{array}$ & $\begin{array}{l}225 \\
915 \\
100\end{array}$ & $\begin{array}{l}19.8 \\
80.2\end{array}$ \\
\hline Cyclodialysis & $\begin{array}{l}\text { Yes } \\
\text { No } \\
\text { Missing data }\end{array}$ & $\begin{array}{r}19 \\
1128 \\
93\end{array}$ & $\begin{array}{r}1.7 \\
98.3\end{array}$ \\
\hline Peripheral iridectomy & $\begin{array}{l}\text { Yes } \\
\text { No } \\
\text { Missing data }\end{array}$ & $\begin{array}{r}1220 \\
15 \\
5\end{array}$ & $\begin{array}{r}98.9 \\
1.2\end{array}$ \\
\hline Antimetabolites & $\begin{array}{l}\text { Yes } \\
\text { No } \\
\text { Missing data }\end{array}$ & $\begin{array}{r}79 \\
1156 \\
5\end{array}$ & $\begin{array}{r}6.4 \\
93.6\end{array}$ \\
\hline Releasable sutures & $\begin{array}{l}\text { Yes } \\
\text { No } \\
\text { Missing data }\end{array}$ & $\begin{array}{r}200 \\
1017 \\
23\end{array}$ & $\begin{array}{l}16.4 \\
83.6\end{array}$ \\
\hline
\end{tabular}


Table 2. Dose and method of intraoperative antimetabolite application

\begin{tabular}{|c|c|c|c|c|c|c|}
\hline \multirow[b]{2}{*}{ Variable } & \multirow[b]{2}{*}{ Category } & \multicolumn{2}{|c|}{ 5-Fluorouracil } & \multicolumn{3}{|c|}{ Mitomycin-C } \\
\hline & & $n$ & $\%$ & & $n$ & $\%$ \\
\hline \multirow[t]{4}{*}{ Dose $(\mathrm{mg} / \mathrm{ml})$} & $<25.0$ & 16 & 30.8 & 0.2 & 2 & 40.0 \\
\hline & 25.0 & 32 & 61.5 & 0.4 & 2 & 40.0 \\
\hline & 50.0 & 4 & 7.7 & 0.5 & 1 & 20.0 \\
\hline & Missing data & 18 & - & & 0 & - \\
\hline \multirow[t]{3}{*}{ Application } & Sponge & 62 & 91.2 & & 5 & 100.0 \\
\hline & Subconjunctival & 6 & 8.8 & & 0 & \\
\hline & Missing data & 2 & - & & 0 & - \\
\hline Duration of sponge & 1 & 1 & 1.7 & & 0 & 0.0 \\
\hline \multirow{5}{*}{ a. plication (min) } & 2 & 2 & 3.3 & & 0 & 0.0 \\
\hline & 3 & 10 & 16.7 & & 1 & 20.0 \\
\hline & 4 & 1 & 1.7 & & 1 & 20.0 \\
\hline & 5 & 46 & 76.7 & & 3 & 60.0 \\
\hline & Missing data & 2 & - & & 0 & - \\
\hline
\end{tabular}

allow comparison with the literature) and visual field stability at 1 year. Both tonometric measures were further defined as qualified or unqualified depending on whether the patient was on post-operative anti-glaucoma medication or not respectively. Cases undergoing further trabeculectomy during this period were regarded as failures.

Associations between explanatory variables characterising consultant practice (self-reported specialist glaucoma interest, university or district general hospital practice, activity level and region) and the main outcome measure of success were measured by the chisquared test with statistical significance at $p<0.05$. A consultant's activity level was determined by the number of trabeculectomies they reported performing in the year prior to the survey. This was recoded as a categorical variable for ease of tabulation as there was no difference in statistical inference when treated as either a continuous or categorical variable. South West was used as baseline for chi-square analysis of region and outcome because it was numerically the largest category and had an average success rate.

\section{Results}

Clinical outcome data from the visit closest to 1 year following trabeculectomy were available for 1240 (85.3\%) cases (reasons for failure of follow-up are reported elsewhere ${ }^{1}$ ). There were no significant differences in demographic or baseline clinical characteristics between those patients for whom final clinical outcome data were available and those for whom they were not (full tabulation available on the Eye website).

\section{Operative details}

Trabeculectomy was performed on 627 (50.6\%) right eyes and $613(49.4 \%)$ left eyes. Eight hundred and sixteen $(68.8 \%)$ cases were performed with local anaesthetic and $424(35.7 \%)$ with general anaesthetic. Peribulbar anaesthesia was the most frequently used local technique. In 727 (58.6\%) cases the consultant performed the surgery. Table 1 presents further details of the surgical technique. Intraoperative antimetabolites were used in $79(6.4 \%)$ cases. 5-Fluorouracil (5FU) accounted

Table 3. Differences in trabeculectomy technique between specialist and non-specialist consultants

\begin{tabular}{|c|c|c|c|c|}
\hline Variable & Category & Specialist $n(\%)$ & Non-specialist $n(\%)$ & $p$ value \\
\hline Type of anaesthetic & $\begin{array}{l}\text { Peribulbar } \\
\text { General } \\
\text { Retrobulbar } \\
\text { Sub-Tenon's } \\
\text { Subconjunctival } \\
\text { Topical }\end{array}$ & $\begin{aligned} 118 & (43.7) \\
113 & (41.9) \\
21 & (7.8) \\
11 & (4.1) \\
7 & (2.6) \\
& 0\end{aligned}$ & $\begin{array}{rr}437 & (47.7) \\
311 & (33.9) \\
84 & (9.2) \\
48 & (5.2) \\
31 & (3.4) \\
6 & (0.7)\end{array}$ & $\begin{array}{c}- \\
0.047 \\
0.771 \\
0.693 \\
0.682 \\
0.204\end{array}$ \\
\hline Traction suture & $\begin{array}{l}\text { Superior rectus } \\
\text { Corneal }\end{array}$ & $\begin{array}{r}195(80.9) \\
46(19.1)\end{array}$ & $\begin{array}{rr}729 & (92.7) \\
57 & (7.3)\end{array}$ & $\begin{array}{c}- \\
<0.0001\end{array}$ \\
\hline Scleral flap & $\begin{array}{l}\text { Rectangular } \\
\text { Triangular } \\
\text { Other }\end{array}$ & $\begin{array}{r}196(71.8) \\
62(22.7) \\
15 \quad(5.5)\end{array}$ & $\begin{array}{rr}747 & (80.8) \\
19 & (15.0) \\
38 & (4.1)\end{array}$ & $\begin{array}{c}- \\
0.002 \\
0.193\end{array}$ \\
\hline Intraoperative antimetabolites & $\begin{array}{l}\text { No } \\
\text { Yes }\end{array}$ & $\begin{array}{r}238(85.3) \\
41(14.7)\end{array}$ & $\begin{array}{r}918(96.0) \\
38 \quad(4.0)\end{array}$ & $\begin{array}{c}- \\
<0.0001\end{array}$ \\
\hline Post-operative 5FU & $\begin{array}{l}\text { No } \\
\text { Yes }\end{array}$ & $\begin{array}{r}265(94.6) \\
15 \quad(5.4)\end{array}$ & $\begin{array}{rr}940 & (97.9) \\
20 & (2.1)\end{array}$ & $0 . \overline{-}$ \\
\hline Releasable sutures & $\begin{array}{l}\text { No } \\
\text { Yes }\end{array}$ & $\begin{array}{r}256(91.4) \\
24 \quad(8.6)\end{array}$ & $\begin{array}{r}918(95.6) \\
42 \quad(4.4)\end{array}$ & $\begin{array}{c}- \\
0.001\end{array}$ \\
\hline
\end{tabular}

5FU, 5-fluorouracil. 


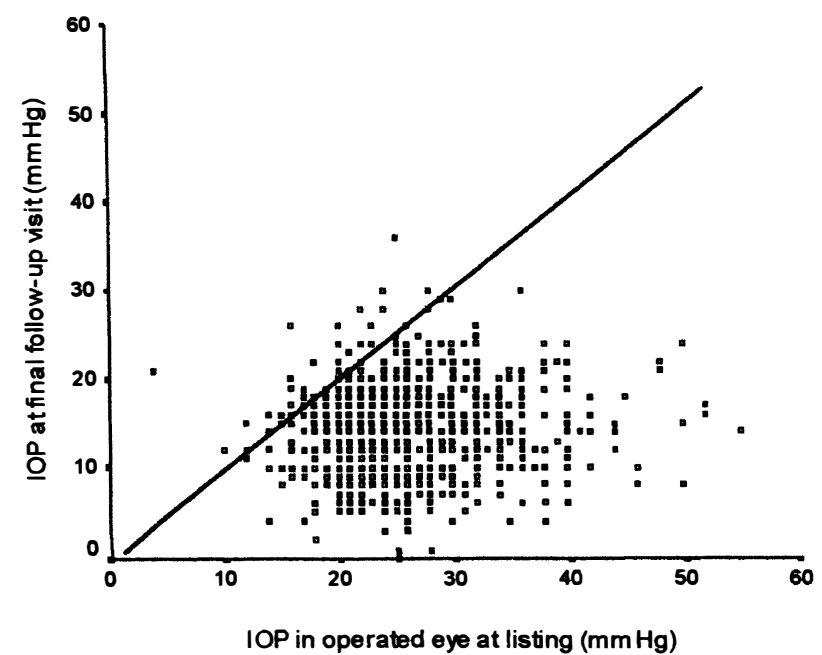

Fig. 1. Scatterplot of pre-operative and post-operative intraocular pressure.

for $88.6 \%$ of these, mitomycin-C (MMC) for $6.3 \%$ and $\beta$ irradiation for $5.1 \%$. There was wide variation in dosage strength and type and duration of application for $5 \mathrm{FU}$ and MMC (Table 2). 5FU was administered most frequently by a soaked sponge with a median strength of $25 \mathrm{mg} / \mathrm{ml}$. Post-operative topical steroids were used in $1222(98.9 \%)$ cases. Anti-glaucoma drops were prescribed in $157(12.7 \%)$ cases in the year following trabeculectomy.

In $66(5.3 \%)$ cases releasable sutures were released or permanent sutures cut by laser. The bleb was needled in $21(1.7 \%)$ cases and $35(2.8 \%)$ cases had post-operative subconjunctival $5 \mathrm{FU}$ injections. Five $(0.4 \%)$ cases underwent further trabeculectomy in the year following initial trabeculectomy; these cases were regarded as failures.
Consultants with a specialist interest in glaucoma were more likely to use general anaesthesia, a corneal traction suture, a triangular scleral flap, intraoperative antimetabolites, post-operative subconjunctival 5FU and releasable sutures (Table 3 ).

\section{Outcomes of trabeculectomy}

The mean IOP at the final follow-up visit was $14.4 \mathrm{mmHg}$ (95\% CI 14.2-14.7). This represents a mean absolute drop of $11.8 \mathrm{mmHg}(95 \% \mathrm{CI} 11.4-12.2)$ and a mean percentage drop of $42.8 \%$ (95\% CI 41.6-44.0) in the pre-operative IOP. In the scatterplot (Fig. 1) the points below the line of unity represent eyes in which some reduction in IOP was achieved by the final follow-up visit. These IOP calculations include those patients on post-operative anti-glaucoma medications.

Patients with normal tension glaucoma (NTG) had significantly lower final intraocular pressures compared with primary open angle glaucoma (POAG) cases, though the proportionate reduction in each group was similar (Table 4). Although there was no statistically significant difference in absolute final IOP between pseudoexfoliation glaucoma (PXG) and POAG cases, the proportionate reduction was significantly higher, reflecting a higher IOP in PXG cases at listing.

\section{Success}

The main outcome measure of success - a final IOP less than two-thirds the pre-operative pressure excluding patients on anti-glaucoma medication (unqualified success) - was achieved in $66.6 \%$ (823 cases, data missing for 4 cases). A qualified success (including patients on

Table 4. Underlying diagnosis, intraocular pressure and success rates

\begin{tabular}{|c|c|c|c|c|}
\hline Diagnosis & $\begin{array}{c}\text { POAG } \\
(n=1105)\end{array}$ & $\begin{array}{c}\text { NTG } \\
(n=51)\end{array}$ & $\begin{array}{c}\text { PXG } \\
(n=64)\end{array}$ & $\begin{array}{c}\text { PDG } \\
(n=20)\end{array}$ \\
\hline \multicolumn{5}{|l|}{ IOP at listing } \\
\hline Mean IOP (mmHg) & 26.29 & 19.96 & 29.09 & 26.10 \\
\hline $95 \% \mathrm{CI}$ & $25.96-6.62$ & $18.73-21.19$ & $26.94-31.24$ & $23.39-28.81$ \\
\hline$p$ value $^{a}$ & - & $<0.0001$ & $<0.0001$ & 0.954 \\
\hline \multicolumn{5}{|l|}{ IOP at final follow-up } \\
\hline Mean IOP (mmHg) & 14.58 & 11.55 & 14.42 & 13.65 \\
\hline $95 \%$ CI & $14.30-14.90$ & $10.30-12.80$ & $13.00-15.84$ & $11.80-15.50$ \\
\hline$p$ value $^{a}$ & - & $<0.0001$ & 0.979 & 0.444 \\
\hline \multicolumn{5}{|c|}{ Proportionate reduction in IOP } \\
\hline Mean percentage drop & 42.5 & 40.0 & 48.3 & 45.1 \\
\hline $95 \%$ CI & $41.3-43.7$ & $33.0-47.1$ & $42.1-54.4$ & $36.2-53.9$ \\
\hline$p$ value $^{a}$ & - & 0.352 & 0.033 & 0.622 \\
\hline \multicolumn{5}{|c|}{ Final IOP $<$ two-thirds pre-operative IOP } \\
\hline$\%$ success rate & 66.2 & 64.0 & 70.3 & 85.0 \\
\hline$p$ value $^{a}$ & - & 0.753 & 0.493 & 0.077 \\
\hline \multicolumn{5}{|c|}{ Post-operative anti-glaucoma medications } \\
\hline No. of cases (\%) & 147 (13.3) & $1(2.0)$ & $9(14.1) 1$ & 0 \\
\hline$p$ value $^{a}$ & - & 0.018 & 0.862 & 0.157 \\
\hline
\end{tabular}

POAG, primary open angle glaucoma; NTG, normal tension glaucoma; PXG, pseudo-exfoliation glaucoma; PDG, pigmentary glaucoma.

${ }^{a} p$ value of diagnostic category compared with baseline (POAG). 


\begin{tabular}{|c|c|c|c|c|c|c|c|c|}
\hline & & & \multicolumn{6}{|c|}{ 'Success' criterion } \\
\hline & & & \multicolumn{3}{|c|}{ Unqualified } & \multicolumn{3}{|c|}{ Qualified } \\
\hline & & & $n$ & \multicolumn{2}{|c|}{$\%$} & $n$ & \multicolumn{2}{|c|}{$\%$} \\
\hline $\begin{array}{l}\text { Final IOI } \\
\text { pre-oper }\end{array}$ & irds & & 823 & \multicolumn{2}{|c|}{66.6} & 878 & \multicolumn{2}{|c|}{71.0} \\
\hline Valid de & & & 1236 & \multicolumn{2}{|c|}{100.0} & 1236 & \multirow{2}{*}{\multicolumn{2}{|c|}{100.0}} \\
\hline Missing & & & 4 & & & 4 & & \\
\hline \multicolumn{3}{|c|}{ Final IOP in $\mathrm{mmHg}$} & $n$ & Valid \% & Cumulative \% & $n$ & Valid \% & Cumulative \% \\
\hline \multirow{7}{*}{\multicolumn{2}{|c|}{$\leqslant 6$}} & 0 & 1 & 0.1 & 0.1 & 1 & 0.1 & 0.1 \\
\hline & & 1 & 2 & 0.2 & 0.2 & 2 & 0.2 & 0.2 \\
\hline & & 2 & 1 & 0.1 & 0.3 & 1 & 0.1 & 0.3 \\
\hline & & 3 & 2 & 0.2 & 0.5 & 2 & 0.2 & 0.5 \\
\hline & & 4 & 6 & 0.5 & 1.0 & 6 & 0.5 & 1.0 \\
\hline & & 5 & 11 & 0.9 & 1.9 & 11 & 0.9 & 1.9 \\
\hline & & 6 & 25 & 2.0 & 3.9 & 26 & 2.1 & 4.0 \\
\hline \multirow{14}{*}{\multicolumn{2}{|c|}{$7-20$}} & 7 & 16 & 1.3 & 5.2 & 17 & 1.4 & 5.3 \\
\hline & & 8 & 71 & 5.7 & 10.9 & 71 & 5.7 & 11.1 \\
\hline & & 9 & 29 & 2.3 & 13.2 & 29 & 2.3 & 13.4 \\
\hline & & 10 & 112 & 9.0 & 22.3 & 115 & 9.3 & 22.7 \\
\hline & & 11 & 32 & 2.6 & 24.9 & 34 & 2.7 & 25.4 \\
\hline & & 12 & 131 & 10.6 & 35.5 & 137 & 11.1 & 36.6 \\
\hline & & 13 & 42 & 3.4 & 38.9 & 44 & 3.6 & 40.1 \\
\hline & & 14 & 118 & 9.5 & 48.4 & 127 & 10.3 & 50.3 \\
\hline & & 15 & 69 & 5.6 & 54.0 & 72 & 5.8 & 56.1 \\
\hline & & 16 & 143 & 11.5 & 65.5 & 157 & 12.7 & 68.8 \\
\hline & & 17 & 53 & 4.3 & 69.8 & 58 & 4.7 & 73.5 \\
\hline & & 18 & 89 & 7.2 & 77.0 & 109 & 8.8 & 82.3 \\
\hline & & 19 & 32 & 2.6 & 79.6 & 40 & 3.2 & 85.5 \\
\hline & & 20 & 55 & 4.4 & 84.0 & 80 & 6.5 & 92.0 \\
\hline \multirow{12}{*}{\multicolumn{2}{|c|}{$\geqslant 21$}} & 21 & 19 & 1.5 & 85.5 & 31 & 2.5 & 94.5 \\
\hline & & 22 & 8 & 0.6 & 86.2 & 21 & 1.7 & 96.2 \\
\hline & & 23 & 3 & 0.2 & 86.4 & 7 & 0.6 & 96.7 \\
\hline & & 24 & 6 & 0.5 & 86.9 & 15 & 1.2 & 98.0 \\
\hline & & 25 & 2 & 0.2 & 87.1 & 4 & 0.3 & 98.3 \\
\hline & & 26 & 2 & 0.2 & 87.2 & 5 & 0.4 & 98.7 \\
\hline & & 27 & 0 & 0 & 87.2 & 0 & 0 & 98.7 \\
\hline & & 28 & 0 & 0 & 87.2 & 3 & 0.2 & 98.9 \\
\hline & & 29 & 1 & 0.1 & 87.3 & 2 & 0.2 & 99.1 \\
\hline & & 30 & 1 & 0.1 & 87.4 & 5 & 0.4 & 99.5 \\
\hline & & 36 & 0 & 0 & 87.4 & 1 & 0.2 & 99.6 \\
\hline & & Total & 1082 & 87.4 & 87.4 & 1233 & 99.6 & 99.6 \\
\hline \multicolumn{3}{|c|}{ Medications } & 151 & 12.2 & 99.6 & NA & NA & - \\
\hline Failures & \multicolumn{2}{|c|}{ Redo trabeculectomies } & 5 & 0.4 & 100.0 & 5 & 0.4 & 100.0 \\
\hline \multirow[t]{3}{*}{ Totals } & \multirow{3}{*}{\multicolumn{2}{|c|}{$\begin{array}{l}\text { Valid denominator } \\
\text { Missing data } \\
\text { Study total }\end{array}$}} & 1238 & 100.0 & 100.0 & 1238 & 100.0 & 100.0 \\
\hline & & & 2 & & & 2 & & \\
\hline & & & 1240 & & & 1240 & & \\
\hline
\end{tabular}

IOP, Intraocular pressure; NA, not applicable.

anti-glaucoma medication) was achieved in $71.0 \%$ (878 cases, data missing for 4 cases). In terms of achieving an IOP less than $21 \mathrm{mmHg}$, the unqualified success rate was $84.0 \%$ (1043 cases, data missing for 2 cases) and the qualified success rate $92.0 \%$ (1138 cases, data missing for 2 cases). An IOP less than $16 \mathrm{mmHg}$ was achieved in
$54.6 \%$ (676 cases, data missing for 2 cases) (Table 5). There were no significant differences in success rates between the different diagnostic categories (Table 4).

Consultants with a specialist interest in glaucoma did not have significantly different success rates from those who did not report a specialist interest (Table 6). Type of

Table 6. Variations in success rates according to specialist interest, type of hospital and activity level

\begin{tabular}{|c|c|c|c|c|}
\hline Variable & Category & Number of cases $(\%)$ & Success rate $(\%)$ & $p$ value \\
\hline \multirow[t]{2}{*}{ Specialist glaucoma interest } & Yes & $280(22.6)$ & $195(69.6)$ & - \\
\hline & No & $960(77.4)$ & $628(65.7)$ & 0.218 \\
\hline \multirow[t]{2}{*}{ Type of hospital } & District general & $888(71.6)$ & $583(65.8)$ & - \\
\hline & University & $352(28.4)$ & $240(68.6)$ & 0.352 \\
\hline \multirow{4}{*}{$\begin{array}{l}\text { No. of trabeculectomies in } \\
\text { year prior to survey }\end{array}$} & $\leqslant 20$ & $344(30.9)$ & $233(65.0)$ & - \\
\hline & $21-39$ & $427(38.4)$ & $285(67.1)$ & - \\
\hline & $\geqslant 40$ & $341(30.7)$ & $226(66.5)$ & 0.833 \\
\hline & Missing data & 128 & - & - \\
\hline
\end{tabular}




\begin{tabular}{lccccc}
\hline & & \multicolumn{4}{c}{ Success rate } \\
\cline { 3 - 6 } Region & Number of cases & IOP $<2 / 3$ pre-op. IOP & $p$ value & IOP $<21 \mathrm{mmHg}$ & $p$ value $^{a}$ \\
\hline South West & 206 & $68.0 \%$ & - & $85.0 \%$ & - \\
Anglia and Oxford & 133 & $66.9 \%$ & 0.841 & $84.2 \%$ & 0.839 \\
Northern Ireland & 11 & $54.5 \%$ & 0.552 & $90.9 \%$ & 0.920 \\
North Thames & 67 & $70.1 \%$ & 0.738 & $83.3 \%$ & 0.740 \\
North West & 122 & $68.0 \%$ & 0.989 & $85.2 \%$ & 0.956 \\
North Yorkshire & 157 & $66.2 \%$ & 0.730 & $84.1 \%$ & 0.804 \\
Scotland & 159 & $59.1 \%$ & 0.081 & $78.6 \%$ & 0.112 \\
South Thames & 127 & $68.5 \%$ & 0.918 & $85.3 \%$ & 0.951 \\
Trent & 97 & $64.9 \%$ & 0.603 & $85.6 \%$ & 0.901 \\
Wales & 51 & $70.6 \%$ & 0.718 & $76.5 \%$ & 0.142 \\
West Midlands & 106 & $69.8 \%$ & 0.739 & $91.5 \%$ & 0.104 \\
\hline
\end{tabular}

${ }^{a}$ Chi-square test (with Yates' correction for small numbers where appropriate) comparing region with baseline region (South West).

hospital and activity level were also not significantly associated with success. There were no significant differences in success rates between regions of the UK (Table 7).

In only $713(57.7 \%)$ cases had a visual field been performed during the year following trabeculectomy. Of these cases, stabilisation of the field was reported in 571 (84.2\%, data missing for 35 cases).

\section{Discussion}

\section{Variations in technique}

Since Cairns' original description of trabeculectomy ${ }^{11}$ numerous modifications have been proposed. The evidence base for many of these consists of singlesurgeon series or unmatched cohort studies although there have been proper intervention studies of site of surgery, ${ }^{12}$ limbus versus fornix-based conjunctival flap, ${ }^{13,14}$ partial versus total tenonectomy, ${ }^{15}$ size of scleral flap and block, ${ }^{16}$ anterior versus posterior approach, ${ }^{17}$ post-operative steroids, ${ }^{18-20}$ releasable sutures, ${ }^{21}$ argon suture lysis, ${ }^{22}$ needling ${ }^{23}$ and antimetabolites. ${ }^{24-28}$ Table 1 shows that there is wide variation in surgeons' techniques. Consultants with a specialist interest in glaucoma were more likely to use general anaesthesia, a corneal traction suture, triangular scleral flap, antimetabolites and releasable sutures.

\section{Intraocular pressure}

A mean final IOP of $14.4 \mathrm{mmHg}$ is within the range reported by other studies (13.6-17.1). ${ }^{6,29-38}$ Fig. 1 shows that the majority of patients experienced a reduction in IOP following trabeculectomy.

Final IOP was significantly lower in NTG cases compared with baseline (POAG), although the proportionate drop was similar. This supports studies reporting that trabeculectomy is effective in achieving a significant IOP reduction in $\mathrm{NTG}^{39}$ which in this survey averaged $40 \%$ of the pre-operative IOP (with only one patient on post-operative anti-glaucoma medication). Higher pre-operative IOPs and a greater magnitude of IOP reduction after trabeculectomy in patients with PXG have been reported before ${ }^{40-42}$ although in our study the final IOP was not significantly different from the POAG group. As pseudoexfoliation is often underdiagnosed $^{43,44}$ it is possible that case misclassification has weakened the differences between the two groups.

\section{Success and failure}

This survey uses a main outcome measure of success that accommodates patients with pre-operative pressures less than $21 \mathrm{mmHg}$ (approximately 15\% of the group). This measure is more clinically appropriate than a cut-off of $21 \mathrm{mmHg}$ for cohorts such as ours which include NTG and POAG cases with pre-operative pressures less than $21 \mathrm{mmHg}$. This approach also recognises as successes patients with high pre-operative pressures in whom there has been a considerable reduction in IOP without reaching $21 \mathrm{mmHg}$ as well as patients with lower preoperative pressures with smaller reductions in IOP. This results in a lower success rate $(66.6 \%)$ than if success were defined more traditionally as a final IOP less than $21 \mathrm{mmHg}$ (84.2\%). Both figures have been reported; the latter allows comparison with the literature but the former is considered a more appropriate reflection of the outcome of trabeculectomy for this cohort.

An unqualified success rate of $84.0 \%$ (IOP $<21 \mathrm{mmHg}$, excluding patients on anti-glaucoma medication) compares favourably with other UK studies. In accordance with these studies, ${ }^{32,37,45-55}$ the success rates are higher when patients on anti-glaucoma medications are included. Studies of primary trabeculectomy, where trabeculectomy is the initial treatment of glaucoma, rather than trabeculectomy after medical treatment has failed, report success rates of approximately $98 \%,{ }^{34,56}$ In this survey primary trabeculectomy accounted for $5.0 \%$ of cases ${ }^{1}$ and therefore makes a minimal contribution to the overall success rate.

Although it was originally thought that trabeculectomy success stabilised within a year of surgery, ${ }^{47,57}$ there is increasing evidence that trabeculectomy failure continues at a steady rate for years post-operatively. ${ }^{8,35,58}$ We chose a follow-up period of 1 year for pragmatic reasons, but it can be anticipated that the success rate is likely to decrease with longer follow-up. 


\section{Consultant characteristics}

Four measures characterising consultants' practice were examined to determine their relationship with success of surgery. None was significantly associated with outcome. The odds of a successful outcome were a fifth higher for consultants reporting a specialist interest in glaucoma, but this was not statistically significant. This may reflect differences in case-mix, as specialist surgeons would be expected to operate on more complex cases with poorer prognoses. However, as this survey was concerned with first-time trabeculectomy for POAG and excluded cases with previous surgery, it is equally plausible that for this patient profile, the difference in performance between specialist and non-specialist is not significant. Examining the relationship between the number of trabeculectomies each consultant reported performing in the year prior to the audit and success served to complete the activity analysis reported in our previous paper. ${ }^{1}$ As there is no association between number of trabeculectomies and outcome, weighting cases according to consultants' levels of activity is not required. Regional success rates varied between $54.5 \%$ and $70.6 \%$. Although the odds of success were almost half for Northern Ireland compared with baseline (South West), the numbers in this category were too small to be statistically meaningful. Region and type of hospital were also examined in the National Cataract Surgery Survey and similarly were not associated with outcome (P. Desai, personal communication). It may be that these indicators are too blunt to act as discriminants for surgical outcome. Further analysis of the associations between success and study factors characterising the patient and surgical technique will be presented in future publications.

\section{Conclusions}

This paper reports widespread variation in the operative technique of trabeculectomy amongst ophthalmic surgeons in the UK. The success rates are generated from a representative sample of UK patients and practitioners and therefore provide valid figures for the production of guidelines and standards for audit at regional, local or individual level. The national success rate (IOP $<21 \mathrm{mmHg}$ ) compares favourably with many studies in the literature. When using the study's main outcome measure of success, a criterion that may be a more clinically relevant measure of success, $66.6 \%$ of patients were successfully controlled. The results of this survey can therefore be used for treatment outcome studies that include patients with NTG or those with POAG whose pre-operative pressures are less than $21 \mathrm{mmHg}$.

\section{References}

1. Edmunds B, Thompson JR, Salmon JF, Wormald RP. The national survey of trabeculectomy. 1. Sample and methods. Eye 1999;13:524-300.
2. Werner EB, Bishop KI, Koelle J, et al. A comparison of experienced clinical observers and statistical tests in detection of progressive visual field loss in glaucoma using automated perimetry. Arch Ophthalmol 1988;106:619-23.

3. Skuta GL, Beeson CC, Higginbotham EJ, et al. Intraoperative mitomycin versus postoperative 5-fluorouracil in high-risk glaucoma filtering surgery. Ophthalmology 1992;99:438-44.

4. Kitazawa Y, Suemori-Matsushita H, Yamamoto T, Kawase K. Low-dose and high-dose mitomycin trabeculectomy as an initial surgery in primary glaucoma. Ophthalmology 1993;100.

5. Feldman RM, Dietze PJ, Gross RL, Oram O. Intraoperative 5-fluorouracil administration in trabeculectomy. J Glaucoma 1994;3:302-7.

6. Nouri-Mahdavi K, Brigatti L, Weitzman M. Outcomes for trabeculectomy for primary open angle glaucoma. Ophthalmology 1995;102:1760-9.

7. Caronia RM, Liebmann JM, Friedman R, Cohen H, Ritch R. Trabeculectomy at the inferior limbus. Arch Ophthalmol 1996;114:387-91.

8. Chen TC, Wilensky JT, Viana MAG. Long-term follow-up of initially successful trabeculectomy. Ophthalmology 1997;104:1120-5.

9. Collaborative Normal-tension Glaucoma Study Group. Comparison of glaucomatous progression between untreated patients with normal-tension glaucoma and patients with therapeutically reduced intraocular pressure. Am J Ophthalmol 1998;126:487-97.

10. Scott IU, Greenfield DS, Schiffman J, et al. Outcomes of primary tracbeculectomy with the use of adjunctive mitomycin. Ophthalmology 1998;116:286-91.

11. Cairns JE. Trabeculectomy. Preliminary report of a new method. Am J Ophthalmol 1968;66:673-9.

12. Sanders R, MacEwen CJ, Haining WM. Trabeculectomy: effect of varying surgical site. Eye 1993;7:440-3.

13. Traverso CE, Tomey KF, Antonios S. Limbal- vs fornix-based conjunctival trabeculectomy flaps. Am J Ophthalmol 1987;104:28-32.

14. Shuster JN, Krupin T, Kolker AE, Becker B. Limbus- v fornixbased conjunctival flap in trabeculectomy: a long-term randomized study. Arch Ophthalmol 1984;102:361-2.

15. Miller KN, Blasini M, Shields B, Ho C. A comparison of total and partial tenonectomy with trabeculectomy. Am J Ophthalmol 1991;111:323-6.

16. Starita RJ, Fellman RL, Spaeth GL, Poryzees EM. Effect of varying size of scleral flap and corneal block on trabeculectomy. Ophthalmic Surg 1984;15:484-7.

17. Konstas AGP, Jay JL. Modification of trabeculectomy to avoid postoperative hyphaema: the 'guarded anterior fistula' approach. Br J Ophthalmol 1992;76:353-7.

18. Roth SM, Spaeth GL, Starita RJ, Birbillis EM, Steinmann WC. The effects of postoperative corticosteroids on trabeculectomy and the clinical course of glaucoma: a fiveyear follow-up study. Ophthalmic Surg 1991;22:724-9.

19. Starita RJ, Fellman RL, Spaeth GL, Poryzees EM, Greenidge $K C$, Traverso CE. Short- and long-term effects of postoperative corticosteroids on trabeculectomy. Ophthalmology 1985;92:938-46.

20. Araujo SV, Spaeth GL, Roth SM, Starita RJ. A ten-year followup on a prospective randomized trial of postoperative corticosteroids after trabeculectomy. Ophthalmology 1995;102:1753-9.

21. Raina UK, Tuli D. Trabeculectomy with releasable sutures: a prospective, randomized pilot study. Arch Ophthalmol 1998;116:1288-93.

22. Bluestein EC, Stewart WC. Tight versus loose scleral flap closure in trabeculectomy surgery. Doc Ophthalmol 1993;84:379-85.

23. Costa VP, Correa M, Kara-Jose N. Needling versus medical treatment in encapsulated blebs: a randomized, prospective study. Ophthalmology 1997;104:1215-20. 
24. Lamba PA, Pandey PK, Raina UK, Krishna V. Short-term results of initial trabeculectomy with intraoperative or postoperative 5-fluorouracil for primary glaucomas. Indian J Ophthalmol 1996;44:157-60.

25. Egbert PR, Williams AS, Singh K, Dadzie P, Egbert TB. A prospective trial of intraoperative fluorouracil during trabeculectomy in a black population. Am J Ophthalmol 1993;116:612-6.

26. Ophir A, Ticho U. A randomized study of trabeculectomy and subconjunctival administration of fluorouracil in primary glaucomas. Arch Ophthalmol 1992;110:1072-5.

27. Rasheed ES. Initial trabeculectomy with intraoperative mitomycin-C application in primary glaucomas. Ophthalmic Surg Lasers 1999;30:360-6.

28. Ruderman JM, Welch DB, Smith MF, Shoch DE. A randomized study of 5-fluorouracil and filtration surgery. Am J Ophthalmol 1987;104:218-224.

29. Ferguson JG, Macdonald R. Trabeculectomy in Blacks: a twoyear follow-up. Ophthalmic Surgery 1976;8:41-3.

30. Huygens M, Vercruysse K, Goethals M, Missotten L. Trabeculectomy: a retrospective long-term follow-up study. Bull Soc Belge Ophtalmol 1990;238:125-35.

31. Jerndal T, Lundstrom M. 330 trabeculectomies: a follow-up study through $1 / 2-3$ years. Acta Ophthalmol 1977;55:52-62.

32. Kidd MN, O'Connor M. Progression of field loss after trabeculectomy: a five-year follow-up. $\mathrm{Br} \mathrm{J}$ Ophthalmol 1985;69:827-31.

33. Lamping KA, Bellows R, Hutchinson BT, Afran SI. Longterm evaluation of initial filtration surgery. Ophthalmology 1986;93:91-100.

34. Migdal C, Gregory W, Hitchings R. Long-term functional outcome after early surgery compared with laser and medicine in open-angle glaucoma. Ophthalmology 1994;101:1651-7.

35. Molteno ACB, Bosma NJ, Kittelson JM. Otago glaucoma surgery outcome study: long-term results of trabeculectomy - 1976 to 1995. Ophthalmology 1999;106:1742-50.

36. Robinson DIM, Lertsumitkul S, Billson FA, Robinson LP. Long-term intraocular pressure control by trabeculectomy: a ten-year life table. Aust N Z J Ophthalmol 1993;21:79-85.

37. Wilson P. Trabeculectomy: long-term follow-up. $\mathrm{Br} \mathrm{J}$ Ophthalmol 1977;61:535-8.

38. Wilson MR. Posterior lip sclerectomy vs trabeculectomy in West Indian Blacks. Arch Ophthalmol 1989;107:1604-8.

39. Hitchings RA, Wu J, Poinoosawmy D, McNaught A. Surgery for normal tension glaucoma. Br J Ophthalmol 1995;79:402-6.
40. Tornqvist G, Drolsum LK. Trabeculectomies: a long-term study. Acta Ophthalmol (Copenh) 1991;69:450-4.

41. Konstas AG, Jay JL, Marshall GE, Lee WR. Prevalence, diagnostic features, and response to trabeculectomy in exfoliation glaucoma. Ophthalmology 1993;100:619-27.

42. Popovic V, Sjostrand J. Course of exfoliation and simplex glaucoma after primary trabeculectomy. Br J Ophthalmol 1999;83:305-10.

43. Ritch R. Exfoliation syndrome: the most common identifiable cause of open-angle glaucoma. J Glaucoma 1994;3:176-8.

44. Konstas AG, Allan D. Pseudoexfoliation glaucoma in Greece. Eye 1989;3:747-53.

45. Cairns JE. Trabeculectomy for chronic simple open angle glaucoma. Trans Ophthalmol Soc UK 1969;89:481-90.

46. Watson P. Trabeculectomy: a modified ab externo technique. Ann Ophthalmol 1970;2:199-205.

47. Ridgway AEA. Trabeculectomy: a follow-up study. Br J Ophthalmol 1974;58:680-6.

48. Watson PG, Barnett F. Effectiveness of trabeculectomy in glaucoma. Am J Ophthalmol 1975;79:831-44.

49. Murray SB, Jay JL. Trabeculectomy: its role in the management of glaucoma. Trans Ophthalmol 1979;99:492-4

50. Zaidi AA. Trabeculectomy: a review and 4-year follow-up. $\mathrm{Br}$ Ophthalmol 1980;64:436-9.

51. Mills KB. Trabeculectomy: a retrospective long-term followup of 444 cases. Br J Ophthalmol 1981;65:790-5.

52. Morrell AJ, Searle AET, O'Neill EC. Trabeculectomy as an introduction to intraocular surgery in an ophthalmic training program. Ophthalmic Surg 1989;20:557-60.

53. Akafo SK, Goulstine DB, Rosenthal AR. Long-term post trabeculectomy intraocular pressures. Acta Ophthalmol (Copenh) 1992;70:312-6.

54. Sanders R. Trabeculectomy in the second eye. Acta Ophthalmol Scand 1996;74:163-5.

55. Briggs MC, Jay JL. Age over 46 years does not affect the pressure lowering effect of trabeculectomy in primary open angle glaucoma. Br J Ophthalmol 1999;83:280-4.

56. Migdal C, Hitchings R. Control of chronic simple glaucoma with primary medical, surgical and laser treatment. Trans Ophthalmol Soc UK 1986;105:653-6.

57. d'Ermo F, Bonomi L, Doro D. A critical analysis of the longterm results of trabeculectomy. Am J Ophthalmol 1979;88:829-35.

58. Popovic V, Sjostrand J. Long-term outcome following trabeculectomy. 1. Retrospective analysis of intraocular pressure regulation and cataract formation. Acta Ophthalmol (Copenh) 1991;69:299-304. 